\title{
In the Philippines, the long wait for free sexual health care continues
}

$\mathrm{T}$ he beginning of April was supposed to mark a watershed in Philippines family planning. Some 14 years after this predominately Catholic country first introduced a bill enshrining the right to free condoms and sex education, the Responsible Parenthood Law was finally passed on Dec. 17, 2012.

The Department of Health was due to implement the law in April. But following 10 petitions by pro-life groups, the Supreme Court on March 19 voted 15 to 5 in favor of suspending the law for 120 days, prompting jubilation among many members of the church and heartache for many others - health workers, womens' groups and most government officials in particular.

The petitions assert that the Responsible Parenthood and Repro- ductive Health Act goes against the constitution, which states that "no person shall be deprived of life" without due legal process.

"Over 100 of us actually held a vigil-rally in front of the Supreme Court in the afternoon following the announcement," says Dr. Junice Melgar, director and founder of Likhaan, a nongovernmental organization (NGO) that operates six sexual health clinics for the urban poor in Manila.

She notes that the fight is anything but over. The Department of Health is helping the government's solicitorgeneral prepare a defence ahead of the start of oral arguments on June 18.

If this succeeds, the law could finally be implemented by the summer.

After decades of government reluctance to go up against the Catholic
Church, the reproductive health challenges in the Philippines remain grave.

On average, 11 Filipino women die every day due to pregnancy-related conditions. The most common causes are hypertension (27\%), hemorrhage (18\%) and unsafe abortions (11\%), according to Department of Health data. In 2011, the maternal mortality rate (MMR) rose to 221 deaths per 100000 live births from 162 per 100000 live births in 2009.

As a result, "the country will not be able to meet its UN Millennium Development Goals target of 52 [deaths per 100 000] MMR in 2015," says Jackylin Robel, head executive assistant at the Commission on Population (POPCOM), an agency of the Department of Health.

Although the new reproductive health law is not expressly designed to

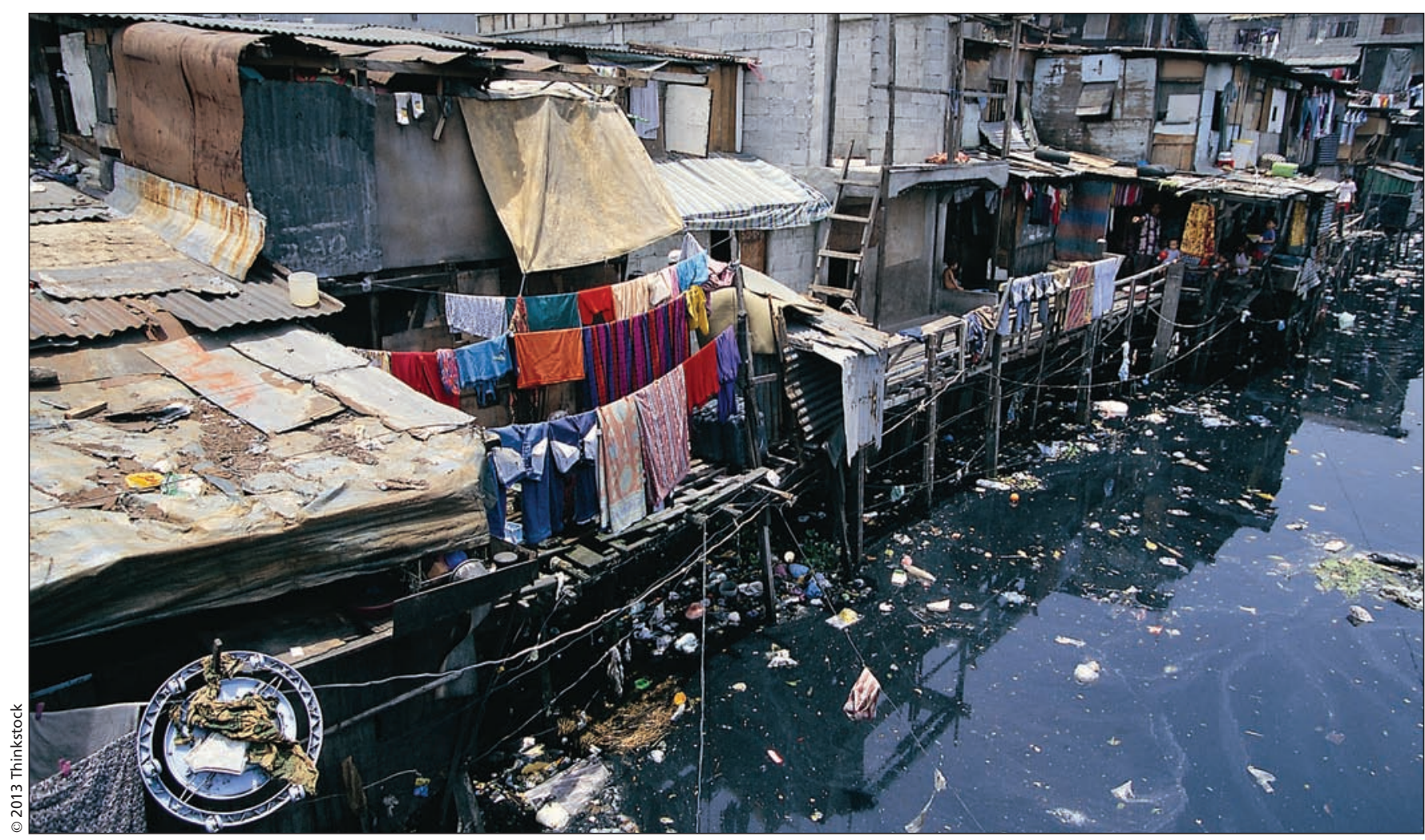

Poverty and a lack of accessibility to medical care and family planning means the maternal mortality rate in the Philippines has increased to 221 deaths per 100000 live births; the UN goal is 52 deaths per 100000 live births. 
slow the Philippines high population growth, it is aimed at offering women better control of how many children they have, helping to fight associated health concerns and poverty, says Robel.

In 2008, women of child-bearing age were having, on average, 3.3 children each, according to POPCOM data. However, a survey shows that women wanted to have 2.4 children.

"This indicates that many couples are not able to achieve their desired fertility goals because of the unmet need in family planning," says Robel.

But will this new reproductive health legislation help tackle this list of concerns when - or if - it finally gets put into practise?

Melgar warns that unless the Department of Health dedicates considerable resources, state family-planning services will prove inadequate. Then there are key concerns that the law has left out, adds Melgar. The Philippines remains one of just a handful of countries in the world with an outright ban on abortion after it was omitted from the new legislation as opposing sides attempted to reach compromise.
Under the new law, Catholic hospitals - which are numerous but account for under half of all hospitals - would remain exempt from providing familyplanning services. Girls below the age of 18 would not be legally permitted access unless they are already parents, or have had a miscarriage, and emergency contraception would remain prohibited in state facilities.

Still, the new law would not only stop local authorities from banning most family-planning services, it would actively require that they provide them. This would be "a major victory," says Magdalena Bacalando, a community health worker for 17 years at a Likhaan clinic in Manila.

Between 1998 and 2007, local authorities initiated a de facto ban on condom distribution and other familyplanning services in Manila when a new pro-life administration took office. Although NGOs like Likhaan were later able to operate without fear of harassment, the city itself was still not providing services.

"In Manila, there were almost no family-planning services for almost 10 years," Bacalando says at Likhaan's tiny, two-storey clinic in slums facing Manila's sprawling port. "Now we have close coordination with the health department. We don't worry anymore that local politicians will stop us from working."

Her clinic offers free education on the contraception options available to couples, providing intrauterine devices (IUDs), condoms and the pill, as well as breast examinations, for free. Only pap smears must be paid for at 100 pesos (\$2.50) per test. Bacalando says it's a model that shows what the new sexual health law could achieve across a country where millions of people struggle to afford and access these services.

Cornelia Tumale, a 46-year-old patient at the Likhaan clinic, has already had six children. She recently decided to have an IUD fitted because she was not capable of financially supporting more children.

In the past, she went to a nearby state hospital to seek family-planning help, but was turned away. "It was banned at that time," she says. - Steve Finch, Manila, the Philippines

CMAJ 2013. DOI:10.1503/cmaj.109-4469 